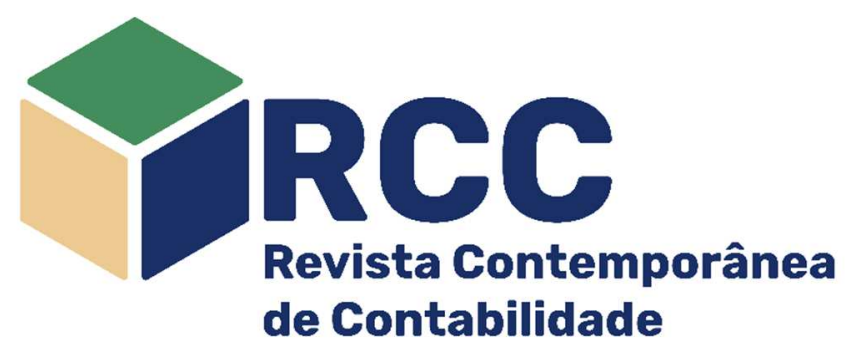

\title{
O goodwill na perspectiva da appreciative inquiry (AI): a inovação transformando o patrimônio intangível
}

\author{
Goodwill from the appreciative inquiry (Al) perspective: innovation transforming intangible capital \\ Goodwill desde la perspectiva de la appreciative inquiry (AI): innovación que transforma el \\ patrimonio intangible
}

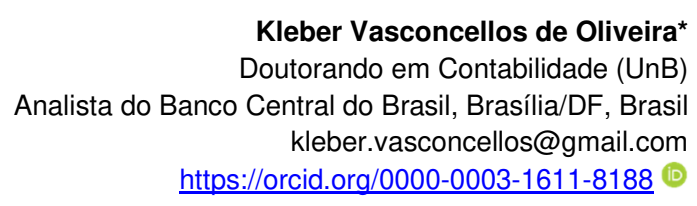

Kleber Vasconcellos de Oliveira*

Central do Brasil, Brasília/DF, Brasil

https://orcid.org/0000-0003-1611-8188

\author{
Paulo Roberto Barbosa Lustosa \\ Doutor em Contabilidade e Controladoria (USP) \\ Professor Titular do Programa de Pós-Graduação em Ciências \\ Contábeis - PPGCONT (UnB), Brasília/DF, Brasil \\ lustosa@unb.br \\ https://orcid.org/0000-0003-4624-197X (1)
}

\author{
Andrea de Oliveira Gonçalves \\ Doutora em Integração da América Latina (USP) \\ Professora Associada do Programa de Pós-Graduação em Ciências \\ Contábeis - PPGCONT (UnB), Brasília/DF, Brasil \\ andreagon@unb.br \\ https://orcid.org/0000-0001-7514-8139 (1)
}

Endereço do contato principal para correspondência* Universidade de Brasília, CCA, Campus Universitário Darcy Ribeiro - Asa Norte, CEP: 70910-900 - Brasília/DF, Brasil

\section{Resumo}

Apresentamos um ensaio teórico a respeito da relação existente entre o goodwill contábil e os ideais e premissas da Appreciative Inquiry (Al). Adotamos também uma nova abordagem sobre o goodwill, caracterizando-o como um estado de riqueza potencial que será convertido em riqueza real no futuro. Este ensaio traz análises e indagações que auxiliarão o aprofundamento das reflexões a respeito desse tão controverso tema da literatura contábil. Indagamos se não seriam as interações preconizadas no que alguns autores chamam de "Revolução Positiva" uma das responsáveis pela geração de ganhos superiores nas organizações? $\mathrm{O}$ ambiente propiciado pela $\mathrm{Al}$ - ao considerar as melhores experiências vivenciadas pelas pessoas - pode ter relação direta com o goodwill que postulamos? A falta de consenso sobre a natureza do goodwill bem como os recentes debates que voltaram à agenda dos normatizadores abrem espaço para novas reflexões críticas e debates epistemológicos sobre o tema.

Palavras-chave: Goodwill; Appreciative Inquiry; Patrimônio Intangível; Organizações

\begin{abstract}
We present a theoretical essay on the relationship between accounting goodwill and the premises of appreciative inquiry (Al). We also adopt a new approach to goodwill, characterizing it as a state of potential wealth that will be converted into real wealth in the future. This essay introduces analyses and inquiries that will help deepen reflections on this very controversial topic in accounting literature. We ask if the interactions recommended in what some authors call the "positive revolution" might be responsible for generating superior earnings in organizations. Considering people's best experiences, can the environment provided by Al be directly related to the goodwill we postulate? The lack of consensus on the nature of goodwill and the recent debates that have returned to the agenda of standard-setters create the opportunity for new critical reflections and epistemological debate on the topic.
\end{abstract}

Keywords: Goodwill; Appreciative Inquiry; Intangible Wealth; Organizations

\section{Resumen}

Presentamos un ensayo teórico sobre la relación entre lo goodwill contable y los ideales y premisas de la 
Appreciative Inquiry (Al). También adoptamos un nuevo enfoque de lo goodwill, caracterizándolo como un estado de riqueza potencial que se convertirá en riqueza real en el futuro. Este ensayo trae análisis e indagaciones que ayudarán a profundizar las reflexiones sobre este tema tan controvertido en la literatura contable. Preguntamos si las interacciones recomendadas en lo que algunos autores llaman la "Revolución Positiva" podrían ser una de las responsables de ganancias superiores en las organizaciones. ¿Puede el entorno proporcionado por la IA - considerando las mejores experiencias vividas por las personas - estar directamente relacionado con lo goodwill que postulamos? La falta de consenso sobre la naturaleza de lo goodwill y los debates recientes que han vuelto a la agenda de los normatizadores abren espacio para nuevas reflexiones críticas y debates epistemológicos sobre el tema.

Palabras clave: Goodwill; Appreciative Inquiry; Patrimonio Intangible; Organizaciones

\section{Introdução: conectando o "plug" do conhecimento}

O mais intangível dos intangíveis - o goodwill - tem crescido de modo significativo nos últimos anos, atingindo cifras importantes em diversas organizações. Essa é uma tendência observada mundialmente, na qual os investimentos estão gradativamente migrando dos ativos físicos para os intangíveis (Bloom, 2009; Lev, 2018). O consenso da literatura é que esse é um dos mais controversos e debatidos temas da contabilidade (Mccarthy \& Schneider, 1995; Chalmers et al., 2011; Betancourt \& Irving, 2019). Além disso, alguns autores questionam se o goodwill realmente seria um ativo ou até mesmo afirmam não o ser (Johnson \& Petrone, 1998; Seetharaman et al., 2006; Gore \& Zimmerman, 2010; Lustosa, 2017). O International Financial Reporting Standard - IFRS 3 define o goodwill como um ativo que representa benefícios econômicos futuros resultantes de outros ativos adquiridos em uma combinação de negócios, os quais não são individualmente identificados e separadamente reconhecidos. Essa característica permite diferenciá-lo dos demais ativos intangíveis, visto que estes são, necessariamente, individualizados no balanço patrimonial, e podem - diferentemente do goodwill - ser vendidos ou transferidos para outra entidade.

Para Martins et al. (2010), o goodwill é caracterizado como um ativo intangível decorrente da capacidade de uma empresa em gerar lucros superiores ao normal (lucros residuais). Ele surge nas organizações por meio da sinergia entre todos os ativos - registrados contabilmente ou não - e outros aspectos (como a gestão, a localização, a força de vendas, fidelidade dos clientes etc.), e é mensurado pela diferença entre o valor da empresa e o seu patrimônio líquido avaliado a valores de mercado. A academia também entende o goodwill como algo que foi desenvolvido (e que está sempre em desenvolvimento) dentro da entidade, representando habilidades e capacidade da entidade e de elementos de variadas naturezas que o compõem (Martins, 2002). Davis (1992) apresenta uma metáfora para o goodwill, salientando que o valor registrado para ele no balanço patrimonial é um "plug" ou número residual. Assim, "o plug é a diferença entre o preço total pago por uma empresa e o valor de mercado justo (FMV) de seus ativos líquidos identificáveis, incluindo ativos intangíveis para os quais um FMV pode ser medido razoavelmente" (p. 3).

Lustosa (2017) adota uma abordagem alternativa para o entendimento do goodwill, baseando-se em conceitos econômicos empregados no sistema de informação de gestão econômica - GECONi. Nesta abordagem, o foco de análise é a mensuração das decisões gerenciais com vistas à obtenção de cada margem de contribuição (receitas menos custos) utilizando-se o conceito de custo de oportunidade (Coase, 1937, 1990). Como o objeto de mensuração é cada evento econômico representado por decisão(ões) gerencial(is), o autor desmembra o valor econômico da empresa em: (i) "patrimônio físico", que é obtido quando todos os ativos e passivos, resultantes de transações já ocorridas ou implementadas, são mensurados pelos seus respectivos custos de oportunidade (são os ativos/passivos individualmente identificados, tangíveis ou intangíveis, e refletidos no balanço patrimonial); (ii) "patrimônio intangível" representado pela diferença entre o valor econômico da empresa (valor presente dos lucros econômicos futuros esperados) e o patrimônio físico. Segundo o autor, o patrimônio intangível (PI) é a verdadeira natureza do goodwill; não um ativo per si, mas um estado de riqueza potencial que será ou não será convertido em riqueza real no futuro. O PI - ou goodwill - se refere a ideias, planos e intenções, ou seja, decisões ainda não consubstanciadas em troca física de ativos ou transações implementadas. Em um negócio de continuidade, o PI é realizado por sua conversão em patrimônio físico (PF) e é simultaneamente renovado por novas ideias, planos e estratégias da gestão da empresa.

Abordagem similar a esta já era debatida desde o trabalho de Myers (1977), na qual o autor afirma que uma parte significativa dos valores de mercado de muitas empresas é contabilizada por "ativos ainda não existentes" (p. 150). Ainda nesta linha de raciocínio, Ramanna e Watts (2012), destacam que o valor do goodwill é função de futuras ações de gestão, incluindo a implementação da estratégia da empresa. Destarte, assim como Carlin (2019) conclama a contabilidade a seguir uma nova jornada para além das partidas dobradas rumo à tecnologia do blockchain, este ensaio convida o leitor para uma reflexão que vai além dos paradigmas contábeis tradicionais de mensuração. O objetivo é fomentar uma reflexão não apenas sobre a dinâmica do goodwill com o patrimônio físico da empresa, mas também, sobre a própria natureza do goodwill. É essa relação que dá vida às organizações! O capital intelectual das empresas (parte integrante do goodwill) é um fenômeno de interações, transformações e complementaridades (Cabrita \& Vaz, 2006).

Neste ensaio, seguimos esta abordagem em especial e adotamos o entendimento do goodwill como 
drivers de valor latentes nas mentes dos gestores que serão incorporados aos ativos que existirão no futuro. Estes últimos é que serão capazes de gerar lucros residuais. A abordagem da visão baseada em recursos (RBV) também segue essa característica, destacando que os recursos e capacidades que residem dentro da organização são a fonte para desenvolver vantagens competitivas sustentáveis. No entanto, essa vantagem competitiva ocorre apenas quando há uma situação de heterogeneidade e imobilidade desses recursos (Peteraf, 1993; Madhani, 2010). Dentre esses recursos, os ativos intangíveis - em especial o goodwill, por conta de sua heterogeneidade e imobilidade - são mais propensos a contribuir para que as empresas atinjam e sustentem um desempenho superior quando combinados ou integrados com outros recursos (Reed et al., 2006).

Em paralelo com o raciocínio anterior, abordamos a Appreciative Inquiry (Al) cujo contexto pode ser entendido como sendo parte da abordagem preconizada tanto nos pressupostos idealizados no campo da Psicologia Positiva - estudo científico das emoções, do caráter, forças, virtudes e das intuições positivas das pessoas - quanto no campo da "Pesquisa-Ação" desenvolvida a partir dos estudos de Kurt Lewin (1944) (Marujo et al., 2007; Meireles \& Lobo, 2012). A Appreciative Inquiry surge a partir da tese de doutoramento de David Cooperrider, em 1986 nos EUA, como um novo método de investigação com a ambição de expandir a visão inicial de Kurt Lewin sobre pesquisa-ação, onde teoria e ação falam sinergicamente uma com a outra (Cooperrider \& Srivastva, 1987; Grieten et al., 2018). No ano seguinte, Cooperrider e Srivastva (1987) publicaram o primeiro artigo sobre a Al que, ao tempo em que condenavam a falta de novas ideias geradas pela pesquisa-ação convencional, propunham a Al como um método com maior probabilidade de criar novas ideias, imagens e teorias que levariam a inovações sociais (Bushe, 2011). A Al tem suas raízes no desenvolvimento organizacional e nas estratégias que ajudam as organizações a se transformarem (Aziz et al., 2018) e possui uma abordagem diferente, ao instigar diretamente a colaboração, sem treinamento de funcionários nem resolução de problemas (Heslop et al., 2018). Um aspecto que diferencia a Al de outras metodologias de pesquisa-ação participativa, que tendem a começar com foco na correção de problemas, é que ela se concentra em explorar as ideias positivas que as pessoas possuem no que fazem e, em seguida, tenta descobrir maneiras pelas quais isso pode ser construído (Boyd \& Bright, 2007; Cooperrider, 2013).

Considerando essas premissas, indagamos se não seriam as habilidades dos gestores, modo de administrar, ideias e estratégias, motivação e capacidade inovadora dos colaboradores etc., o verdadeiro PI da empresa? Caso afirmativo, não seria esse PI uma riqueza latente capaz de se materializar em PF e gerar ganhos econômicos? Essa materialização do PF também é reflexo da sinergia do corpo funcional da organização que, quanto mais motivado, capacitado e comprometido com a mudança, melhor apresenta sua capacidade de resposta ao ambiente competitivo em que se está inserido. Rego et al. (2007) sustentam que as pessoas produzem mais quando sentem que realizam um trabalho com significado para as suas vidas e quando sentem que os seus valores e os da organização estão alinhados. Certamente, o PI de uma organização pode ganhar força em vários ambientes de gestão, no entanto, no ambiente da Al, ao considerar as melhores experiências vivenciadas pelas pessoas dentro de uma organização, esse PI ganha mais força e se diferencia daquele ambiente no qual as empresas buscam a detecção e solução de (antigos) problemas. Assim, a Al teria o potencial de alavancar resultados e criar um ambiente propício para ampliação do desenvolvimento organizacional e do capital intelectual. Cooperrider e Whitney (2005) afirmam que a Al tem sido usada para otimizar a satisfação do cliente, o engajamento dos funcionários, a competitividade de custos e receitas, bem como as habilidades das empresas para atender às necessidades da sociedade.

A partir dos conceitos ora destacados e seguindo uma abordagem interpretativa, apresentamos este ensaio teórico sobre a relação entre o goodwill e a abordagem preconizada na Al. Sob essa perspectiva, não objetivamos apresentar conclusões definitivas a esse ou àquele respeito, mas incitar a reflexão por parte dos leitores com base nas discussões apresentadas. Na forma ensaística, "a orientação é dada não pela busca das respostas e afirmações verdadeiras, mas pelas perguntas que orientam os sujeitos para as reflexões mais profundas" (Meneghetti, 2011, p. 321). O objetivo é a construção do conhecimento conjunto no campo da ciência contábil por meio de discussões construtivas conjuntas para se atingir novos insights. Dessa forma, objetivamos apresentar um novo ponto de vista em relação aos temas ora levantados, bem como um novo "ângulo de visão" para o goodwill, o que não é tarefa fácil, dada a complexidade de se descrever essa relação. Arendt (2008) afirma que "se uma coisa suporta muitos pontos de vista é justamente porque é altamente complexa, intrincada, bem organizada, 'objetivamente bela'. Não se trata de relativismo, mas de relatividade" (p. 8). Tratamos de um conhecimento pouco desenvolvido pela literatura, carecendo de maiores estudos a respeito, o que não o invalida - pelo contrário, torna-se desafiador. A contribuição esperada neste ensaio decorre das mais variadas reflexões críticas e novos debates epistemológicos que venham a ocorrer a respeito do tema. Esperamos fomentar novas discussões, reflexões e estudos adicionais - inclusive por meio de análises positivistas.

O tema apresenta-se bastante contemporâneo. Normatizadores e preparadores de demonstrações financeiras vêm buscando uma forma definitiva para sua contabilização, no entanto encontrar uma solução ideal para o tratamento do goodwill continua sendo desafiador para a comunidade contábil (Martins, 2002; Powell, 2003; Carvalho, 2015; Betancourt \& Irving, 2019). Tanto o "Financial Accounting Standards Board" (FASB) quanto o "International Accounting Standards Board" (IASB) têm projetos em andamentoii para repensar o tratamento do goodwill. Tais projetos vêm recebendo comentários e contribuições mistas de 
usuários, preparadores e auditores sobre o atual modelo baseado apenas na redução ao valor recuperável alguns apoiam o modelo atual, outros apoiam um retorno ao modelo de amortização e outros ainda apoiam um método híbrido de ambos. Isso colocou os holofotes de volta no assunto (Betancourt \& Irving, 2019). Wen e Moehrle (2016) afirmam que o goodwill é um construto econômico complexo que está novamente na agenda do FASB. Devido a essa complexidade, o FASB revisou a contabilização e evidenciação do goodwill várias vezes ao longo dos anos em contínuas tentativas de melhoria. Para Carvalho (2015), o goodwill constitui um clássico e controverso tema contábil que tem gerado profundas discussões sem que até hoje se tenha encontrado uma solução consensual.

Após esse contexto inicial, dividimos este ensaio teórico em mais cinco seções, que são desenvolvidas seguindo o ciclo de implementação da Al bem como a trajetória da formação do PI. A próxima seção apresenta o início do ciclo da Al, abordando o momento do surgimento das ideias no âmbito da administração. A seção 3 destaca a importância do compartilhamento do conhecimento e também apresenta como as ideias são desenhadas e como serão estruturadas em um modelo exequível. A seção 4 trata da última fase do ciclo da $\mathrm{Al}$ e destaca o futuro da organização. Na seção 5 discutimos como as organizações são valorizadas por suas ideias inovadoras. A seção 6 destaca alguns números de goodwill e estudos de casos com a abordagem da Al, bem como nossas conclusões, considerações finais e sugestões de pesquisas futuras.

\section{Eureka: surge uma nova ideia!}

Com o avançar da era da informação, o mundo se torna mais interconectado e a informação e o conhecimento fluem cada vez mais rápido entre as pessoas e as organizações, fazendo com que as mudanças e transformações organizacionais se deem em ritmos cada vez maiores. Mas para que as transformações aconteçam, é necessário primeiramente que exista $(\mathrm{m})$ (boas) ideia(s) nas mentes dos gestores e/ou da alta administração. Em um contexto mais geral, podemos entender que uma empresa nasce a partir de uma (boa) ideia de alguém ou de um grupo de pessoas. Nesta fase, ela possui apenas PI (ideias, planos, estratégias, etc). Para Sarasvathy (1998), uma ideia é qualquer um (ou uma combinação) dos seguintes itens: (i) um produto ou serviço; (ii) uma tecnologia/inovação; e (iii) uma necessidade de mercado. Quando a empresa morre, ela possui apenas PF (ativos que serão utilizados para liquidação do passivo). Entre esses dois extremos - que equivale à empresa em continuidade - a empresa funciona de modo a ir "tangibilizando" aquele PI, e este, por sua vez, é renovado à medida que novas ideias/planos/estratégias retroalimentam o processo de tomada de decisões.

É nesse contexto organizacional que destacamos os ciclos do aprendizado tratados na Al, os quais podem contribuir sobremaneira na disseminação do conhecimento, a fim de que as estratégias e planos ainda não implementadas possam ocorrer de maneira mais produtiva. O processo da Al é resumido por Troxel (2002, p. 6) em duas etapas: (i) a tarefa de pesquisa é identificar e valorizar o melhor do "o que é" dentro da organização. Na primeira etapa, o objetivo da avaliação é explorar os principais temas e forças importantes para a organização; (ii) a tarefa de pesquisa então prevê o que "poderia ser". Quando o melhor do que foi identificado e é valorizado e os valores são recontados, a mente naturalmente começa a procurar algo a mais; começa-se a vislumbrar novas possibilidades. A valorização do que é melhor leva a "Envisionar" o que pode ser. "Envisionar" significa permitir-se ser inspirado pelo que se vê. Cooperrider e Whitney (2005) explicam que esse processo perpassa por um ciclo de atividades denominado "ciclo 4D" (Figura 1), que é, resumidamente, entendido como: (i) Discovery: Mobilizar toda uma investigação do sistema para o núcleo positivo da mudança; (ii) Dream: O que o mundo está nos chamando a ser; (iii) Design: Criar proposições de possibilidade da organização ideal; (iv) Destiny: Fortalecer a capacidade afirmativa de todo o sistema.

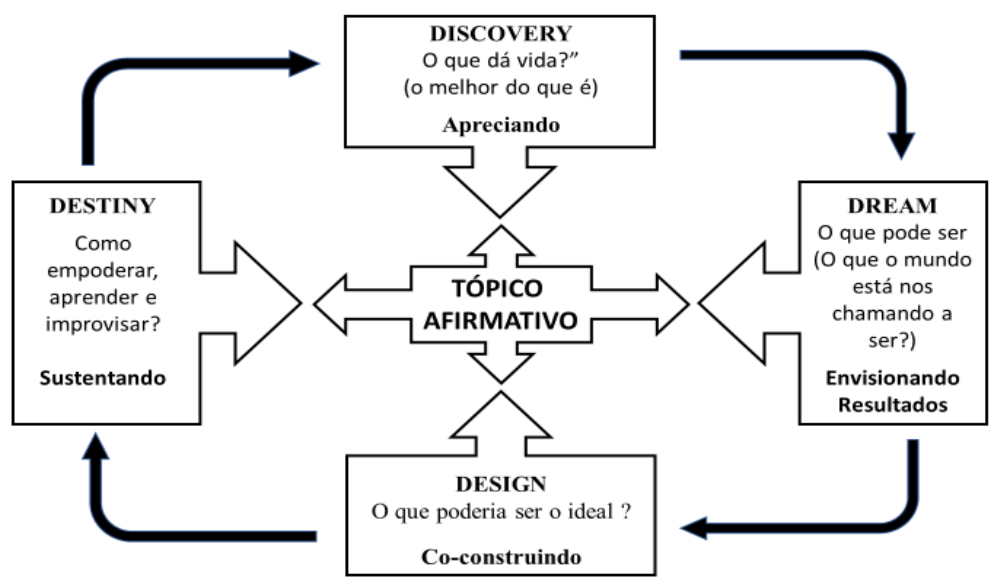

Figura 1 - ciclo 4D

Fonte: Elaboração própria, com base em Cooperrider e Whitney (2005). 
Ainda segundo os autores, no centro do ciclo está a escolha do tópico afirmativo. É a parte mais importante de qualquer Al. Em nosso entendimento, talvez estejamos falando do "coração" da Al, considerando que ela será o motor das fases seguintes. Na escolha deste tópico, é fundamental entender que ele deve ser criteriosamente e cuidadosamente escolhido e deve envolver questões afirmativas e que foram em algum momento relacionadas com as melhores experiências vividas pela organização. Tal escolha pode estar baseada em qualquer coisa que uma organização considere estratégica e humanamente importante. Pode ser sobre processos técnicos, eficiências financeiras, questões humanas, oportunidades de mercado, responsabilidades sociais ou qualquer outra coisa (Cooperrider \& Whitney, 2005). O desafio é fazer perguntas que deliberadamente foquem nos fatores que contribuem para o funcionamento do sistema no seu melhor. As perguntas são projetadas para incentivar os participantes a pesquisar histórias que incorporem esses tópicos afirmativos. Os participantes são encorajados a desenvolver um olhar que valorize a capacidade e 0 sistema humanos (Gergen et al., 2004).

Sveiby (1998) afirma que "as pessoas são os únicos verdadeiros agentes na empresa. Todos os ativos e estruturas - quer tangíveis ou intangíveis - são resultado das ações humanas. Todos dependem das pessoas, em última instância, para continuar a existir" (p. 9). A partir dessa premissa podemos entender que o processo de geração de riqueza em uma organização, não obstante a revolução tecnológica, perpassa inicialmente pelo conhecimento humano. Quotidianamente são tomadas inúmeras decisões - humanas, certamente - no ambiente empresarial que influenciam e interferem no seu sucesso e são por elas influenciadas, determinando níveis de qualidade do trabalho (Dutra, 2010). Assim, todos os níveis hierárquicos são chamados a colaborarem na criação de novos conhecimentos, cada qual fazendo a sua parte, o seu melhor.

Essa diferenciação dos papéis exercidos na organização necessita de uma dinâmica sincronizada, uma interação harmoniosa entre eles objetivando a criação do conhecimento organizacional, que pode ser entendida como a "capacidade da organização de criar novo conhecimento, difundi-lo na organização como um todo e incorporá-lo a produtos, serviços e sistemas" (Nonaka \& Takeuchi, 1997, p. 8, grifo nosso).

Resta claro que as ideias, formas de pensar e administrar dos gestores, bem como a capacidade contributiva por parte dos colaboradores de uma organização podem alavancar seu potencial organizacional e, consequentemente, seus resultados. Quanto melhor e mais criativa for a ideia, bem como mais rapidamente colocada em prática, maiores as chances de sucesso e geração de valor para a empresa. É como se pudéssemos dizer que de nada (ou pouco) adiantaria as ideias de mentes brilhantes como Leonardo da Vinci, Beethoven ou Nikola Tesla, se suas ideias não se transformassem em um PF como a Mona Lisa, a 9a sinfonia ou a transmissão da corrente alternada, só para citar alguns exemplos. As ideias são concebidas, amadurecidas e colocadas em prática, transformando-se em PF. A partir de então, quando a empresa entra em funcionamento, ela vai construindo suas vantagens competitivas intangíveis, tais como a marca institucional e dos seus produtos, a capacidade gerencial e tecnológica diferenciada, o capital intelectual, a motivação dos funcionários, a satisfação e lealdade dos clientes, etc. Mas esse PI não existe por si só, não possui valor econômico por "apenas existir" em uma organização: na verdade, ele é canalizado, direcionado para a finalidade (missão) da firma. Portanto, o PI, apesar de ser valorado em uma combinação de negócios na forma de goodwill, não existe separadamente do PF (ativos, passivos, produtos e serviços).

As fases "Discovery" e "Dream" estão mais fortemente ligadas a esse contexto inicial de surgimento de novas ideias. Conforme resumido por Whitney e Trosten-Bloom (2001):

...a fase Discovery é uma busca para identificar histórias positivas e espalhá-las por toda a organização. Ela traz em foco as coisas que dão vida e energia para as pessoas, seu trabalho e sua organização [...] desloca o equilíbrio da atenção organizacional do que não está funcionando para o que é e para o que possivelmente funcionará no futuro; [...] A fase Dream é um momento para grupos de pessoas se engajarem em pensar grande, pensar fora da caixa e pensar fora dos limites do que foi no passado. É o momento de as pessoas descreverem seus desejos e sonhos por seu trabalho, suas relações de trabalho e sua organização (Whitney \& Trosten-Bloom, 2001, pp. 4-5).

Observa-se a importância da ampla participação do corpo funcional, pois é ele que está à frente da cadeia produtiva e consegue observar mais de perto as fraquezas e virtudes do processo. Na fase "Dream", os participantes identificam seus valores essenciais positivos e os aplicam ao seu futuro ideal, já que esta fase envolve a criação de uma visão orientada para os resultados do potencial descoberto e sua relação com questões de propósito superior (Tittle, 2018; Gray et al., 2019). É nesta fase que se prolifera a capacidade de surgimento de ideias criativas e que poderão auxiliar a alta administração no processo de tomada de decisão que, por sua vez, irá se refletir no PF da empresa. Portanto, ao sustentarmos o goodwill como patrimônio intangível das organizações, estamos afirmando que as qualidades, virtudes e ações humanas são drivers de valor para o PF. Ambos (PI e PF) atuam "emaranhadamente" no processo de geração de lucros residuais.

A literatura predominante destaca que o goodwill está relacionado à capacidade da empresa em obter lucros residuais (Martins, 1972, Johnson \& Petrone, 1998; Wen \& Moehrle, 2016). No entanto, Ma e Hopkins (1988) afirmam que "para entender a natureza do goodwill, é necessário ir além da questão da mensuração e perguntar por que existem lucros residuais?" (p. 76). Segundo os autores, o uso de um ativo em combinação com outros ativos leva a uma interação que afeta favoravelmente a produtividade da empresa - chamada 
também de sinergia da interação de ativos - e que resulta em ganhos superiores. Ora, o "pensar fora da caixa e pensar fora dos limites do que foi no passado", permite criar uma interação entre novas ideias (PI) e os futuros ativos (PF) com vistas aos lucros residuais.

Quando uma empresa decide realizar uma combinação de negócios, seus gestores certamente avaliam os prós e contras da fusão/aquisição levando em consideração a capacidade de geração de resultados positivos do negócio e os comparam com outras alternativas possíveis de investimento. Os gestores de diferentes níveis participam da análise e são aconselhados pela alta administração sobre o ganho potencial da combinação. Com base em sua avaliação e aconselhamento, é tomada uma decisão sobre a fusão (Mirvis \& Marks, 1992; Calipha et al., 2010). Destacamos nesse espectro a perspectiva abordada na Al como forma de potencializar o goodwill adquirido. Quando se busca um ambiente propício para adoção de novas ideias - com participação de todo corpo funcional, considerando o que de melhor há dentro da organização, propiciando a motivação dos colaboradores, salientando tópicos afirmativos, dentre outros aspectos da Al - possibilita-se a criação de um ambiente propício para a sinergia da interação de ativos (em seu mais amplo sentido!).

\section{A metáfora do "rúgbi": passando a bola para avançar como uma unidade!}

Neste tópico buscamos inspiração na metáfora abordada por Nonaka e Takeuchi (1997) para apresentar uma discussão a respeito da importância do compartilhamento do conhecimento inovador. Essa transmissão de conhecimento não se dá de forma definida ou estruturada, ou ainda de forma linear ou sequencial: "o movimento da bola no rúgbi nasce da interação entre os membros da equipe no campo" (Nonaka \& Takeuchi, 1997, prefácio vii). Qualquer empresa detém um dado conhecimento organizacional, que é sua capacidade de executar harmoniosamente atividades e processos que as pessoas não conseguiriam fazer isoladamente. É isso que cria valor aos seus produtos/serviços que são ofertados aos seus clientes. O conhecimento traduz-se nos produtos, serviços e imagem que a organização apresenta para seus stakeholders (Brito, 2008).

Primeiramente, cabe abordar quais as formas distintas de conhecimento existem em uma organização. Uma ampla literatura destaca duas formas de conhecimento: explícito e tácito, sendo o primeiro altamente codificado e transmissível em linguagem formal e sistemática; já o conhecimento tácito é abstrato, não-verbalizável, intuitivo e só pode ser comunicado através do envolvimento ativo do próprio detentor do conhecimento. É aprendido através de experiências colaborativas (Cavusgil et al., 2003; Hussi, 2004). A conversão de conhecimento tácito em explícito é crítica para o sucesso de uma empresa, pois é um prérequisito para o processo de ampliação do conhecimento e aprendizado organizacionais (Herschel et al., 2001). Segundo Cavusgil et al. (2003), empresas que criam e usam o conhecimento de forma rápida e eficaz são capazes de inovar com mais rapidez e sucesso. Os autores discutem a importância do ambiente externo na obtenção do conhecimento e encontram evidências empíricas de que (i) a transferência de conhecimento tácito contribui significativamente para que as empresas desenvolvam grande capacidade de inovação; (ii) a experiência colaborativa entre as empresas também desempenha um papel importante na transferência de conhecimento tácito; (iii) empresas com maior experiência colaborativa podem se beneficiar mais dessa transferência de conhecimento tácito. O ponto chave na criação do conhecimento é justamente a interação entre conhecimentos tácito e explícito em vez de agirem separadamente (Hussi, 2004).

Nessa fase de interação e compartilhamento de ideias, destacamos - além das fases anteriores que também propiciam essa interação - a fase "Design". As fases "Discovery" e "Dream" encorajam os participantes a pensar sobre novas possibilidades, enquanto a fase "Design" usa as propostas provocativas para instigar os participantes na criação de ações em torno das possibilidades (Tittle, 2018). Whitney e Trosten-Bloom (2001), apontam que na fase "Design", os membros da organização e stakeholders "recriam a 'arquitetura social' da organização, de modo que tudo sobre a organização reflete e responde ao passado mais positivo e ao maior potencial da organização" (p. 5). Essa fase é fundamental para sustentar mudanças positivas e responder ao potencial mais positivo e mais alto da organização. Fundamentados no que de melhor tem sido, bons projetos de apreciação abordam todos os três elementos necessários para uma mudança organizacional eficaz: continuidade, novidade e transição (Fernando, 2010). É o momento, segundo Varona (2004, p. 23), "de gerar proposições visionárias reais que permitam desenhar uma visão da organização como um excelente lugar para trabalhar". Nesta etapa, os membros da organização decidem que proposições serão executadas e como lograr êxito na realização de seus sonhos para a organização por meio de um plano de ação.

Esse compartilhamento de conhecimento gerando um aprendizado entre os membros da organização significa um salto na qualidade, na especialização, nas habilidades e, por que não, na motivação dos diversos colaboradores, entre os diferentes níveis hierárquicos. Essa sinergia de conhecimentos agrega valor econômico para uma empresa. Para Glautier e Underdown (2001), o goodwill pode ser descrito como a soma daqueles atributos intangíveis de um negócio que contribuem para o seu sucesso, tais como localização favorável, uma boa reputação, a capacidade e habilidade dos seus empregados e administradores e seus relacionamentos duradouros com credores, fornecedores e clientes. Postulamos que esse conjunto sinérgico de capacidade/habilidade do corpo funcional - que se alastra entre seus membros por meio da transmissão 
de conhecimento no ambiente da $\mathrm{Al}$ - propicia o cenário ideal para o surgimento de produtos/serviços inovadores gerando, consequentemente, ganhos de escala para organização. Isso é o goodwill que defendemos! é aquele algo a mais que cada empresa em particular pode absorver para si, e que entendemos que está interconectado com a Al.

Para Citolin (2009), a Al, diferenciando-se das abordagens tradicionais, pode se constituir em uma importante ferramenta de suporte à inovação, pois a troca de experiências, diálogo e visão coletiva do futuro, faz com que se crie o aprendizado e o comprometimento necessários para o surgimento da inovação (por exemplo, melhoria dos processos existentes, adoção de novos processos, criação de novos produtos/serviços, ou nas próprias práticas gerenciais). Resta claro que para agregar valor, 0 compartilhamento de conhecimento nas organizações precisa ser um "jogo limpo" - livre de sentimentos como, egoísmo, inveja ou ciúme - um "jogo destravado", sem medo ou receio de se expor e, ao mesmo tempo, com mentes abertas para receber novas ideias. Deve ser também um jogo sem faltas ou penalidades que acarretem cartões amarelo ou vermelho. As pessoas precisam se sentir encorajadas a jogar esse jogo. Um jogo participativo de passar e receber "a bola" com o desejo incessante de fazer gols, digo, de aumentar o conhecimento organizacional e, consequente, a sua capacidade inovativa.

A bola que é passada de um jogador para outro encerra a compreensão compartilhada da razão de ser da empresa, o rumo que está tomando [...] e como tornar esse mundo realidade. Insights, intuições e pressentimentos são levados em consideração. É isso que a bola contém - ou seja, ideias, valores e emoções (Nonaka \& Takeuchi, 1997, prefácio xi).

\section{2001: uma odisseia no espaço}

Nesta seção, nos referimos ao futuro a ser percorrido pela organização. Mas não é um futuro incerto como sugere o famoso filme que serve de título para este tópico. É um futuro que será alcançado por meio de objetivos factíveis e construído de maneira compartilhada, combinada. É o momento de se vislumbrar coletivamente, por meio do que foi construído nas fases anteriores, como alcançar o sonho que foi desenhado. Como as pessoas vão levar o conhecimento adquirido para esse futuro almejado? Aliás, essa questão nos faz lembrar de outro tema relacionado ao ano de 2001, o do samba-enredoiii: "Desse mundo louco, de tudo um pouco eu vou levar pra 2001. Avançar no tempo e nas estrelas. Fazer meu Ziriguidum". De todo o conhecimento compartilhado e também adquirido pelos colaboradores, cada um leva um pouco para a construção desse futuro inovador. Essa é a fase "Destiny (ou Delivery)", na qual os compromissos são feitos para garantir que o produto da fase "Design" seja realizado. Nessa fase, indivíduos se comprometem com aplicações e planos de ação.

A mudança, certamente, ocorre em todas as fases da Al, pois o processo fornece um espaço aberto para que os funcionários possam colaborar bem como avançar nas mais variadas questões da organização. No entanto, é na fase "Delivery" que se concentram especificamente os compromissos pessoais e organizacionais, bem como o "caminhar adiante" (Whitney \& Trosten-Bloom, 2001, p. 6). Ludema et al. (2003) afirmam que a fase "Destiny" "é um convite para construir o futuro por meio de inovação e ação", haja vista que "as pessoas encontram maneiras inovadoras de ajudar a levar a organização para mais perto do ideal" (p. 11). Acreditamos que nessa fase é a hora de "arregaçar as mangas", buscar uma integração organizacional ainda mais forte e colocar em prática as metas estabelecidas nas fases anteriores. Seria a hora de implantar as melhorias que vão se materializar no PF e torná-lo possivelmente mais valioso que antes. Nessa fase a entidade começa a ver os resultados de todo o processo se concretizando, se materializando na forma de agir e inovar das pessoas. É também o momento de semear o terreno organizacional de transformação e das melhores práticas. Esta última fase é, em certo sentido, tanto um fechamento quanto o começo do resto da vida da organização (Fernando, 2010).

Isso sugere que, paralelamente, o goodwill também vai se materializando economicamente, ou seja, convertendo-se em PF e gerando lucros residuais. O goodwill, como parte integrante dos ativos intangíveis, pode ser caracterizado como uma síntese de vários outros elementos intangíveis presentes na organização (como flexibilidade da gestão, reputação, tecnologia diferenciada, localização, capital intelectual, lealdade de clientes, motivação de empregados, etc.), cuja "interação harmônica desses ativos com o ambiente interno e externo da empresa produzem efeitos sinérgicos capazes de gerar retornos econômicos em excesso para a companhia" (Lustosa, 2017, p. 2). Nessa fase final, parece ficar mais evidente ainda a interconexão entre a abordagem da Al com o goodwill que postulamos no presente ensaio. Essas forças não reconhecidas separadamente começam a surgir desde a fase "Discovery", vão se incorporando nas fases seguintes até se "materializar" definitivamente na forma do goodwill reconhecido pelo mercado na fase "Destiny" - pelo menos até começar um novo ciclo de aprendizado organizacional, o que poderia até provocar um aumento desse goodwill. Essa fase final visa criar uma cultura e estrutura de aprendizagem contínua, inovação, improvisação e mudança (Fernando, 2010).

Após destacarmos o ciclo 4D que apresenta as fases de implantação da $\mathrm{Al}$, cumpre também destacar os seus princípios norteadores, ou seja, as correntes doutrinárias que fundamentam a Al. Apresentamos, resumidamente, esses cinco princípios com base em Cooperrider e Whitney (2005): (i) Princípio 
Construcionista: diz respeito à coletividade organizacional, em vez do individual, agindo proativamente para guiar o destino da empresa. Para Bushe e Kassam (2005), este princípio afirma que o "como sabemos e o que fazemos" estão intimamente interligados (p. 166); (ii) Princípio da Simultaneidade: "a investigação e a mudança não são momentos separados. São momentos totalmente entrelaçados e emaranhados" (Cooperrider, 2013, p. 26). A mudança começa a acontecer no momento em que se iniciam os primeiros questionamentos no processo de investigação. Investigação é intervenção; (iii) Princípio Poético: a história de uma organização é constantemente coautoria, ou seja, é decorrente das histórias que as pessoas contam umas às outras cotidianamente. Passados, presentes ou futuros são fontes infinitas de aprendizado e inspiração; (iv) Princípio Antecipatório: nossas imagens positivas do futuro conduzem nossas ações positivas. Nossas ações de hoje são antecipações do que vislumbramos e desejamos no futuro; e (v) Princípio Positivo: construir e sustentar o momento da mudança requer grandes quantidades de sentimento positivo e vínculo social. Quanto mais positiva a pergunta que fazemos em nosso trabalho, mais duradouro e bem-sucedido é o esforço de mudança.

\section{As organizações vistas como cérebros}

Neste tópico fazemos referência a Gareth Morgan, no seu livro "Imagens da Organização", para apresentar mais algumas reflexões a respeito da interação proposta no presente ensaio. Ao defendermos o goodwill como aquele intangível que está nas ideias dos gestores e colaboradores ainda não consubstanciadas em patrimônio físico, defendemos que as organizações são valorizadas pelo que pensam e conseguem colocar em prática. Ambiente de ideias inovadoras, juntamente com a capacidade de executar rapidamente essas transformações (inclusive de suas próprias estruturas organizacionais e de produtos/serviços), são instrumentos que potencializam o valor de mercado das organizações na forma de goodwill. No entanto, isso não é tarefa simples! Morgan (2000) questiona: "é possível criar 'organizações que aprendem', com capacidade de serem tão flexíveis, elásticas e engenhosas quanto o funcionamento do cérebro?" (p. 91). Nesse cenário desafiador, o autor destaca a necessidade de haver uma inter-relação da organização: (i) como cérebro processador de informações; (ii) como sistemas complexos capazes de aprender; e (iii) como sistemas holográficos que combinam características centralizadas e descentralizadas. Organizações com mais habilidades adaptativas a mudanças ambientais, de tendências e de preferências de clientes (existentes e potenciais), são as que sobreviverão a esse cenário moderno, no qual as empresas precisam pensar a frente e vislumbrar novos negócios e mercados, internacionalização, descontinuação de negócios etc.

Entendemos que o mercado precifica positivamente a capacidade adaptativa das empresas, fazendo com que estas valham (muito) mais do que os valores apresentados nas suas demonstrações financeiras. Imbuídos dessa visão, as empresas podem (na verdade, devem!) sinalizar a força do seu PI para o mercado. Alguns autores consideram que os atuais relatórios financeiros não refletem ou não capturam adequadamente os vetores de valor que dominam a nova economia (Lev \& Zarowin, 1999; Kang \& Gray, 2011) visto que a fonte do valor econômico não é mais a produção de bens materiais, mas a criação de capital intelectual (Chen et al., 2005). Dessa forma, as notas explicativas, os relatórios anuais, os relatórios voluntários, as páginas da internet, dentre outras ferramentas, são fontes de informação valiosa para os investidores, pois permitem que a administração evidencie o seu PI para todos os stakeholders. Isso contribui sobremaneira para que o investidor possa mensurar a capacidade de geração de resultados da empresa (além dos números contábeis). No entanto, mensurar fidedignamente esse "algo a mais", esse PI, não é algo trivial. Para Martins (2002), discorrer sobre goodwill é uma tarefa difícil e que perpassa por vários assuntos diferenciados, e até mesmo conflitantes. É um tema bastante debatido até os dias de hoje tanto no meio acadêmico quanto no mercado de capitais, não obstante ser um assunto relativamente antigo, haja vista as características da economia atual.

Wen e Moehrle (2016) definem o goodwill como aqueles valores pagos em excesso ao valor justo dos ativos líquidos identificáveis para uma aquisição de negócios. Subentende-se que esse "prêmio" pago para assumir o controle de um negócio está diretamente relacionado aos lucros em excesso no futuro sobre os mesmos ativos existentes antes da realização da transação entre as partes. Surge então uma pergunta: como os mesmos ativos que não geraram retornos em excesso para a empresa adquirida gerarão esses lucros residuais para a empresa adquirente? A resposta que postulamos neste ensaio é que são as forças gerenciais, ideias a serem implementadas, o capital intelectual, enfim, os ganhos de escala implementados sob a forma de administrar esses ativos que proporcionarão os resultados anormais para uma empresa que adquire outra (totalmente ou em parte). Esse ganho adicional é visualizado antecipadamente pelos gestores que decidem então pela aquisição de um negócio.

Este ensaio sustenta que o prêmio pago na combinação de negócios é decorrente das decisões gerenciais que serão implementadas e que estão relacionadas à capacidade intelectual da adquirente - em primeiro lugar - somadas, ou não, com determinadas características da adquirida. Esse goodwill (PI) adquirido ainda será transformado em PF no futuro, pois "todos os ativos e estruturas - quer tangíveis ou intangíveis - são resultado das ações humanas. Todos dependem das pessoas, em última instância, para continuar a existir" (Sveiby, 1998, p. 9, tradução e grifo nossos). Esse PI pode também ser "exportado" por meio de aquisições de empresas em um cenário transnacional. Frésard et al. (2017) destacam o papel da 
especialização como fator de internacionalização de empresas - através de aquisição de empresas menos especializadas - e observam que o volume, a direção e a criação de valor estão relacionadas à disposição das empresas adquirentes em implantar vantagens relacionadas a intangíveis móveis sobre ativos transnacionais. Os autores apontam que os ganhos econômicos em negócios transnacionais são maiores quando compradores especializados compram ativos em setores menos especializados de outros países e que a intensidade dos negócios transnacionais é mais forte quando a indústria adquirente se beneficia do capital humano e tecnológico em comparação com o setor adquirido.

Por outro lado, a Al parece fazer parte desse contexto na medida em que ela se refere a uma perspectiva de pesquisa que se destina a descobrir, compreender e fomentar inovações nos arranjos e processos sócio-organizacionais (Cooperrider \& Srivastva, 1987). Observa-se, destarte, que essa metodologia idealizada na (re)descoberta dos pontos fortes de cada experiência vivenciada pelos gestores e colaboradores - em vez de se preocupar com a solução de problemas - busca a promoção e o compartilhamento desse conhecimento visando novas descobertas e inovações nos processos organizacionais em um ambiente de colaboração e harmonia. Por meio da Al, organizações em todo o mundo tem buscado criar mudanças positivas para uma série de questões como: construção de parcerias e alianças, planejamento estratégico, redução do tempo de desenvolvimento de produto, melhoria na moral e na retenção dos funcionários, melhoria na produtividade, qualidade e nas finanças (Cooperrider \& Whitney, 2005).

Importante salientar que a Al postula que as metas e compromissos estabelecidos devem ser plenamente alcançáveis. E isto deve ser considerado em cada uma das fases do ciclo 4D. Cooperrider e Srivastva (1987) destacam que a pesquisa-ação não deve investigar fenômenos que transcendem a competência da razão humana. Questões que não podem ser respondidas não devem ser feitas e questões que não podem ser postas em prática não devem ser exploradas (ou seja, a pesquisa-ação não é um ramo da filosofia política, da poesia ou da teologia). Talvez seja por essa questão que a Al, diferenciando-se de outras abordagens, permite a participação de diversos stakeholders. Para Boyd e Bright (2007), a Al permite o envolvimento de múltiplos stakeholders e, portanto, reflete uma apreciação e respeito pela diversidade e tolerância das diferenças individuais. Além disso, por sua própria natureza, a Al tende a criar intervenções que aumentam o poder da diversidade como um recurso contínuo dentro das organizações.

\section{Para não dizer que não falei dos números}

O crescimento contínuo dos investimentos intangíveis vem ocorrendo de tal forma que Lev (2018) salienta que se tornou a marca registrada das economias desenvolvidas, iniciando mudanças significativas nos modelos de negócios, estratégias e desempenho das empresas. Relatório GIFT (Global Intangible Finance Tracker) de 2019 corrobora essa informação, mostrando que o goodwill vem apresentando comportamento de alta. Ele dobrou de magnitude, passando de US\$ 3 trilhões em 2005 para US\$ 6 trilhões em 2015 e em 2019, esta cifra atingiu US\$ 8,4 trilhões. Além disso, o mesmo relatório afirma que o goodwill divulgado continua a pairar em torno de 8 a $10 \%$ do valor total de uma empresa e que o valor intangível global não divulgado subiu de US \$ 15 trilhões em 2011 para US \$ 35 trilhões em 2016.

Lev (2004) afirma que os ativos intangíveis geram a maior parte do crescimento corporativo e de valor para o acionista. Na verdade, são esses ativos "softs" que dão às empresas de hoje sua vantagem competitiva. Mais especificamente em relação ao goodwill, buscamos ressaltar a sua relevância nas organizações, por meio da Figura 2. Obtivemos os dados de saldos de goodwill de empresas mundiais dos mais variados setores e países entre os anos de 2000 e 2017, que foram obtidos na base de dados Compustat - Capital IQ. A amostra variou de 14.983 (em 2000) a 25.998 (em 2014) empresas. Observa-se a participação média do goodwill de cerca de $5 \%$ dos ativos totais no período.

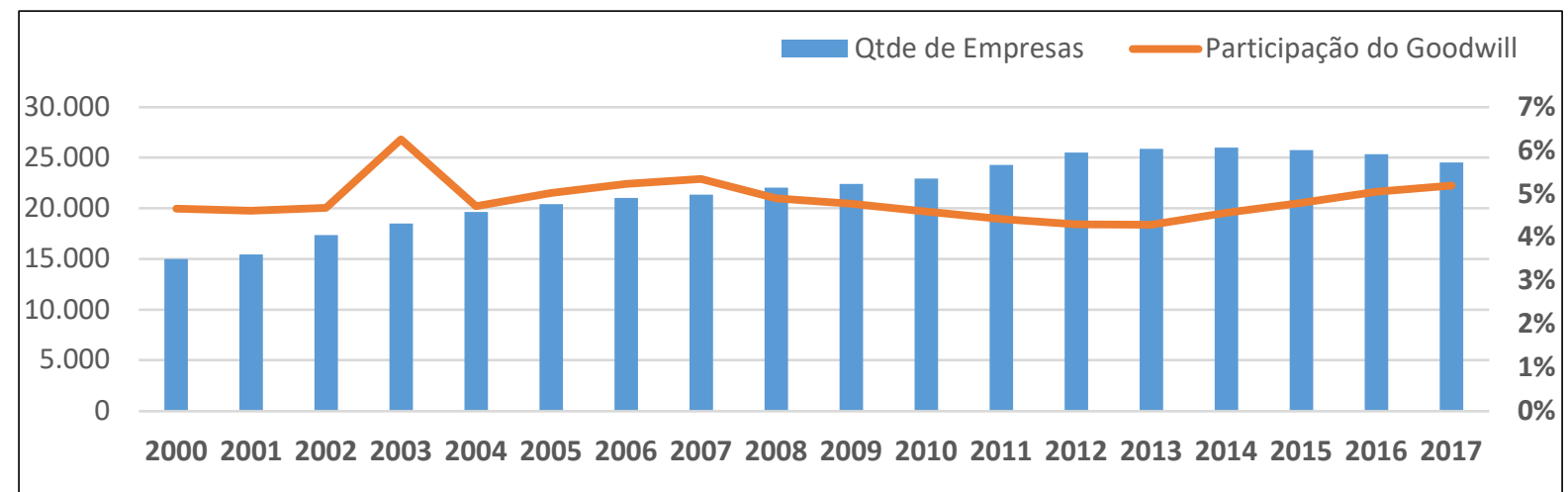

Figura 2 - Participação do Goodwill no ativo total - Mundial

Fonte: elaboração própria, com base nos dados do Compustat

Apresentamos também alguns estudos de casos abordados na literatura da AI para exemplificar os ganhos de sinergia e os reflexos nos resultados de algumas organizações pelo mundo após a adoção da 
abordagem da Al, que foram retirados e adaptados de Cooperrider e Whitney (2005). A partir desses exemplos, indagamos se tais reflexos poderiam estar correlacionados com o reconhecimento do goodwill nessas organizações. A empresa GTE/Verizon ganhou o prêmio ASTD (American Society for Training and Development)iv pelo melhor programa de mudança organizacional do país. Esse prêmio foi baseado em mudanças significativas e mensuráveis nos preços das ações, medidas de pesquisa de moral, qualidade e relacionamento com clientes, dentre outras. A empresa Roadway Express lançou uma iniciativa a fim de reduzir custos e aumentar mais rapidamente os negócios. Quando a Al começou, a ação da empresa estava em torno de US \$ 14 por ação. Em dois anos, as ações subiram para mais de US \$ 40 por ação. Após um processo de fusão em 2003, a empresa combinada foi avaliada em cerca de US $\$ 42$ por ação, devido à força das melhorias da Roadway.

No Brasil, Rocha Loures (2008) destaca que a empresa Nutrimental implantou a Al no ano de 1997 e completou o ciclo 4D em 1999, trazendo resultados em diferentes níveis para a empresa: financeiro, individual e organizacional. As vendas em poucos anos dobraram, enquanto os resultados operacionais decuplicaram. Em um recente estudo que utilizou a abordagem da Al para otimizar a rede de relacionamentos de uma empresa (capital relacional), Shah et al. (2020) observaram que após a adoção da Al houve uma melhoria significativa nas competências relacionais dos funcionários do departamento de vendas e compras num curto período de três meses após a intervenção. Além disso, a atitude dos funcionários no trato com membros da cadeia de suprimentos e clientes melhorou, assim como a comunicação intraorganizacional.

Apesar das histórias de sucesso, a Al - assim como qualquer outro tipo de abordagem - também é cercada por algumas críticas e preocupações. O estudo de Bushe e Kassam (2005), com vinte casos de uso de $\mathrm{Al}$, mostrou que apenas sete (35\%) apresentaram resultados transformacionais, ou seja, inovações na mudança organizacional. Além disso, alguns autores chamam a atenção para a questão do viés para positividade, o que pode cegar o pesquisador para uma parte da realidade, ou seja, os déficits, lacunas e problemas (Grieten et al., 2018). Dessa forma, o foco em histórias e experiências positivas pode acabar escondendo ou camuflando algumas experiências organizacionais negativas dos participantes, reprimindo histórias potencialmente importantes e significativas para a empresa (Bushe, 2011).

Para Gergen et al. (2001), os meios específicos de fomentar a Al derivam da ênfase construcionista na narrativa. As pessoas possuem suas histórias de vida, as quais muitas delas derivam de histórias de superação, valores, beleza e alegria. "Dentro de uma organização, são recursos valiosos, quase como dinheiro no banco (...) E ao ouvir essas histórias, estimula-se a confiança de que, de fato, a visão pode ser realizada" (p. 698, tradução e grifo nossos). Com efeito, eles soltam os poderes da mudança criativa. Para Rocha Loures (2008), quando uma empresa é inovadora nesse processo, os resultados são alcançados simultaneamente ao aprendizado das pessoas. Não é necessário tempo adicional para reflexão, internalização da mudança e aprendizado das novas atitudes e competências, o que torna o processo de mudança organizacional bastante dinâmico e eficaz.

As questões aqui abordadas auxiliam na reflexão e parecem confluir para semelhanças que poderiam, pelo menos em parte, explicar o reconhecimento do goodwill. Defendemos que os elementos positivos (ou tópicos afirmativos) constituem as forças intangíveis "sem vida útil definida", cujo efeito monetário está embutido nos valores econômicos do PF (estoques, máquinas, contas a receber, etc) e PI (ideias, planos de inovação, estratégias, etc) da empresa. Essa interrelação se destaca ainda mais, na medida em que a Al propicia o exercício do diálogo como meio de transformação. A partir dele, indivíduos transbordam o seu melhor em termos de criatividade e inovação em um ambiente de cooperação. É nessa janela de oportunidade que se cria o conhecimento organizacional capaz de fazer com que as organizações valham (muito) mais do que o apontado nos balanços. No entanto, o círculo virtuoso apresentado neste ensaio precisa estar constantemente se renovando para que não se deprecie, como um "circuito duplo" definido em Morgan (2000). Segundo o autor,

...para aprender e mudar, os membros da organização precisam ser capazes de entender os pressupostos, referência e normas que regem a atividade atual e de desafiá-los e mudá-los quando necessário (...) O aprendizado de circuito duplo depende do que às vezes é descrito como a arte de enquadrar e reenquadrar... (Morgan, 2000, p. 102).

Argote et al. (1990) sugerem que o conhecimento adquirido na produção se deprecia rapidamente (muito mais rapidamente do que a taxa de rotação da mão-de-obra), ou seja, há um componente substancial do aprendizado organizacional que deprecia rapidamente e entender o porquê disso é uma boa questão para pesquisas futuras.

Os insights trazidos neste ensaio apontam para oportunidades de pesquisas futuras a fim de fomentar novas discussões e reflexões. Dada a exiguidade de pesquisas empíricas e reflexões críticas nessa linha (Van der Haar \& Hosking, 2004), sugerimos o aprofundamento de pesquisas como: análise da curva de crescimento do PF após processos de combinação de negócios com pagamento de goodwill; análises interpretativistas e positivistas sobre a relação do PI com temas relacionados à inovação como: startups, inteligência artificial, big data, machine learning, etc.; estudos empíricos que investiguem a relação entre PF e PI; abordagens críticas a respeito da manutenção do goodwill por tempo indeterminado. Neste último caso, indagamos se esse conjunto sinérgico, que caracteriza o goodwill, não sofre depreciação à medida que vai 
se materializando no PF? Nesse caso, será que não estaria ocorrendo em diversas empresas o duplo reconhecimento do goodwill: o adquirido e o gerado internamente? Ou ainda, o goodwill poderia ser considerado despesa (em vez de ativo)? A literatura tem mostrado que a maior parte dos processos de aquisições e fusões são considerados falhos em entregar valor ao acionista (Calipha et al., 2010; Marks \& Mirvis, 2011), e o aprofundamento das pesquisas sobre o goodwill pode auxiliar na compreensão desse motivo. Além disso, tais questões, dentre outras, podem ajudar a compreender a real natureza do goodwill, trazendo contribuições para o processo normativo conduzido pelos principais reguladores mundiais.

\section{Referências}

Arendt, R. J. J. (2008). Maneiras de pesquisar no cotidiano: Contribuição da teoria do ator-rede. Psicologia \& Sociedade, 20, 7-11. https://doi.org/10.1590/S0102-71822008000400003

Argote, L., Beckman, S. L., \& Epple, D. (1990). The persistence and transfer of learning in industrial settings. Management Science, 36(2), 140-154. https://doi.org/10.1287/mnsc.36.2.140

Aziz, R. C., Hashim, N. A. A. N., \& Awang, Z. (2018). Tourism Development in Rural Areas: Potentials of Appreciative Inquiry Approach. Journal of Tourism, Hospitality and Culinary Arts, 10(1), 59-75.

Betancourt, L., \& Irving, J. H. (2019). The Challenge of Accounting for Goodwill: Impact of a Possible Return to Amortization. The CPA Journal, 89(11), 46-51. Disponível em:

https://www.cpajournal.com/2019/11/27/the-challenge-of-accounting-for-goodwill/.

Bloom, M. (2009). Accounting for Goodwill. Abacus, 45(3), 379-389. https://doi.org/10.1111/i.1467$\underline{6281.2009 .00295 . x}$

Boyd, N. M., \& Bright, D. S. (2007). Appreciative Inquiry as a mode of action research for community psychology. Journal of Community Psychology, 35(8), 1019-1036. https://doi.org/10.1002/jcop.20208

Brito, L. M. P. (2008). Gestão do Conhecimento - instrumento de apropriação pelo capital do saber do trabalhador. Cadernos de Educação FaE/PPGE/UFPel, 30, 135-148.

http://dx.doi.org/10.15210/CADUC.V0I30.1767

Bushe, G. R. (2011). Appreciative inquiry: theory and critique. In Boje, D., Burnes, B. and Hassard, J. (eds), The Routledge Companion to Organizational Change. London: Routledge.

Bushe, G. R., \& Kassam, A. F. (2005). When is Appreciative Inquiry Transformational? A Meta-Case Analysis. The Journal of Applied Behavioral Science, 41(2), 161-181. https://doi.org/10.1177/0021886304270337

Cabrita, M. R., \& Vaz, J. L. (2006). Intellectual Capital and Value Creation: Evidence from the Portuguese Banking Industry. Journal of Knowledge Management, 4(1), 11-20.

Calipha, R., Tarba, S., \& Brock, D. (2010). Mergers and Acquisitions: A Review of Phases, Motives and Success Factors. In Cary L. Cooper \& Sydney Finkelstein (eds.). Advances in Mergers and Acquisitions, vol. 9. Emerald Group Publishing Limited, Bingley, U.K.

Carvalho, C. M. T. (2015). O Goodwill e o seu tratamento contabilístico pós adoção das IFRS: uma análise nas empresas da Euronext Lisbon. Tese (Doutoramento em Contabilidade). Departamento de Economia, Gestão e Engenharia Industrial, Universidade de Aveiro, Aveiro, 271 f.

Cavusgil, S. T., Calantone, R. J., \& Zhao, Y. (2003). Tacit knowledge transfer and firm innovation capability. Journal of Business \& Industrial Marketing, 18(1), 6-21. https://doi.org/10.1108/08858620310458615

Chalmers, K. G., Godfrey, J. M., \& Webster, J. C. (2011). Does goodwill impairment regime better reflect the underlying economic attributes of goodwill? Accounting and Finance, 51(3), 634-660.

https://doi.org/10.1111/j.1467-629X.2010.00364.x

Chen, M-C., Cheng, S-J., \& Hwang, Y. (2005). An empirical investigation of the relationship between intellectual capital and firms' market value and financial performance. Journal of Intellectual Capital, 6(2), 159-176. https://doi.org/10.1108/14691930510592771

Citolin, F. (2009). Uma visão da investigação apreciativa como ferramenta de apoio à gestão do 
aprendizado e inovação. Global Manager, Faculdade da Serra Gaúcha, 9(16), 87-106.

Coase, R. H. (1937). The Nature of the Firm. Economica, 4(16), 386-405. https://doi.org/10.1111/j.14680335.1937.tb00002.x

Coase, R. H. (1990). Accounting and the theory of the firm. Journal of Accounting and Economics, 12(1-3), 3-13. https://doi.org/10.1016/0165-4101(90)90038-6

Cooperrider, D. L. (1986). Appreciative inquiry: Toward a methodology for understanding and enhancing organizational innovation. Doctoral Dissertation (Doctor of Philosophy). Dept. of Organizational Behavior of Case Western Reserve University, Cleveland, $332 \mathrm{f.}$

Cooperrider, D. L. (2013). A contemporary commentary on appreciative inquiry in organizational life. In D. L. Cooperrider, D. P. Zandee, L. N. Godwin, M. Avital, \& B. Boland (Eds.), Organizational generativity: The appreciative inquiry summit and a scholarship of transformation. Emerald Group Publishing Limited, Bingley, U.K.

Cooperrider, D. L., \& Srivastva, S. (1987). Appreciative Inquiry in organizational life. In R. Woodman and W. Pasmore (Eds.). Research in organizational change and development. JAI Press Inc.

Cooperrider, D. L., \& Whitney, D. (2005). Appreciative Inquiry: A Positive Revolution in Change. San Francisco, CA: Berrett-Koehler.

Davis, M. (1992). Goodwill accounting: Time for an Overhaul. Journal of Accountancy, 173(6), 75-83.

Dutra, M. C. (2010). Comunicação e trabalho: as (im)possibilidades da investigação apreciativa. Tese (Doutorado em Comunicação Social). Faculdade de Comunicação Social, Pontifícia Universidade Católica do Rio Grande do Sul, Porto Alegre, $229 f$.

Fernando, M. S. C. L. (2010). Appreciative inquiry: a positive approach to organizational planning and learning. Social Research Reports, 10(2), 3-105. Disponível em http://www.researchreports.ro/images/researchreports/social/srr 2010 v010.pdf.

Frésard, L., Hege, U., \& Phillips, G. (2017). Extending Industry Specialization through Cross-Border Acquisitions. Review of Financial Studies, 30(5), 1539-1582. https://doi.org/10.1093/rfs/hhx008

Gergen, K. J., Mcnamee, S., \& Barrett, F. J. (2001). Toward transformative dialogue. International Journal of Public Administration, 24(7-8), 697-707. https://doi.org/10.1081/PAD-100104770

Gergen K. J., Gergen, M. M., \& Barrett, F. J. (2004). Dialogue: Life and Death of the Organization. In D. Grant, C. Hardy, C. Oswick and L. Putnam (eds). The Handbook of Organizational Discourse. London: Sage.

GIFT - Global Intangible Finance Tracker - An annual review of the world's intangible value. (2019). Brand Finance, November. Disponível em: https://brandfinance.com/wp-content/uploads/1/gift 2.pdf

Glautier, M., \& Underdown, B. (2001). Accounting. Theory and Practice. $7^{\underline{a}}$ ed. Prentice Hall.

Gore, R., \& Zimmerman, D. (2010). Is goodwill an asset? The CPA Journal, 80(6), 46-48.

Gray, S., Treacy, J., \& Hall, E. T. (2019). Re-engaging disengaged pupils in physical education: an appreciative inquiry perspective. Sport, Education and Society, 24(3), 241-255.

https://doi.org/10.1080/13573322.2017.1374942

Grieten, S., Lambrechts, F., Bouwen, R., Huybrechts, J., Fry, R., \& Cooperrider, D. (2018). Inquiring into Appreciative Inquiry: A Conversation with David Cooperrider and Ronald Fry. Journal of Management Inquiry, 27(1), 101-114. https://doi.org/10.1177/1056492616688087

Herschel, R. T., Nemati, H., \& Steiger, D. (2001). Tacit to explicit knowledge conversation: knowledge exchange protocols. Journal of Knowledge Management, 5(1), 107-116.

https://doi.org/10.1108/13673270110384455

Heslop, B., Paul, J., Stojanovski, E., \& Bailey, K. (2018). Organisational Psychology and Appreciative Inquiry: Unifying the Empirical and the Mystical. Al Practitioner, 20(1), 69-90. 
http://dx.doi.org/10.12781/978-1-907549-34-2-11

Hussi, T. (2004). Reconfiguring knowledge management: combining intellectual capital, intangible assets and knowledge creation. Journal of Knowledge Management, 8(2), 36-52.

https://doi.org/10.1108/13673270410529091

IASB - International Accounting Standards Board. (2008). IFRS 3 - Business Combinations. IFRS Foundation.

Johnson, L. T., \& Petrone, K. R. (1998). Is goodwill an asset? Accounting Horizons, 12(3), 293-303. Disponível em: http://dx.doi.org/10.2139/ssrn.143839

Kang, H. H., \& Gray, S. J. (2011). Reporting intangible assets: Voluntary disclosure practices of top emerging market companies. The International Journal of Accounting, 46(4), 402-423.

https://doi.org/10.1016/.intacc.2011.09.007

Lev, B. (2004). Sharpening the Intangibles Edge. Harvard Business Review, 82(6), 109-116.

Lev, B. (2018). Intangibles. New York University - Stern School of Business. SSRN working paper. http://dx.doi.org/10.2139/ssrn.3218586

Lev, B., \& Zarowin, P. (1999). The Boundaries of Financial Reporting and How to Extend Them. Journal of Accounting Research, 37(2), 353-385. http://dx.doi.org/10.2307/2491413

Lewin, K. (1944). The dynamics of group action. Educational Leadership, 1, 195-200.

Ludema, J. D., Whitney, D., Mohr, B. J., \& Griffin, T. J. (2003). The Appreciative inquiry summit: A practitioner's guide for leading large-group change. San Francisco: Berrett-Koehler.

Lustosa, P. R. B. (2017). A New Approach to Accounting Goodwill (and Other Identified Intangibles with Indefinite Useful Lives): Theory and Empirical Evidence. SSRN Working Paper. Disponível em: http://dx.doi.org/10.2139/ssrn.3023311

Ma, R., \& Hopkins, R. (1988). Goodwill - An Example of Puzzle-Solving in Accounting. Abacus, 24(1), 75-85. https://doi.org/10.1111/i.1467-6281.1988.tb00204.x

Madhani, P. M. (2010). Resource Based View (RBV) of Competitive Advantage: an Overview. SSRN Working Paper. Disponível em: http://ssrn.com/abstract=1578704.

Marks, M. L., \& Mirvis, P. H. (2011). Merge Ahead: A Research Agenda to Increase Merger and Acquisition Success. Journal of Business and Psychology, 26(2), 161-168. https://doi.org/10.1007/s10869-011-9219-4

Martins, E. (1972). Contribuição à Avaliação do Ativo Intangível. Tese (Doutorado em Ciências Contábeis). Faculdade de Economia, Administração e Contabilidade. Universidade de São Paulo, São Paulo, 218 f.

Martins, E., Almeida, D. L., Martins, E. A., \& Costa, P. S. (2010). Goodwill: uma análise dos conceitos utilizados em trabalhos científicos. Revista Contabilidade \& Finanças. 21(52), 1-25.

https://doi.org/10.1590/S1519-70772010000100005

Martins, V. A. (2002). Contribuição à Avaliação do Goodwill: Depósitos Estáveis, Um Ativo Intangível. Dissertação (Mestrado em Controladoria e Contabilidade). Curso de Pós-Graduação em Controladoria e Contabilidade, Faculdade de Economia, Administração e Contabilidade da Universidade de São Paulo, São Paulo, $277 \mathrm{f}$.

Marujo, H. A., Miguel Neto, L., Caetano, A., \& Rivero, C. (2007). Revolução positiva: Psicologia Positiva e práticas apreciativas em contextos organizacionais. Comportamento Organizacional e Gestão, 13(1), 115136.

Mccarthy, M. G., \& Schneider, D. K. (1995). Market Perception of goodwill: Some Empirical Evidence. Accounting and Business Research, 26(1), 69-81. https://doi.org/10.1080/00014788.1995.9729499

Meireles, C. A. M., \& Lobo, F. (2012). A Psicologia Positiva e as Organizações. Anais do I Congresso Internacional de Psicologia do Trabalho e das Organizações, $12-13$ julho 2012, Braga. Veritati - Repositório 
Institucional da Universidade Católica Portuguesa. Disponível em: http://hdl.handle.net/10400.14/17031

Meneghetti, F. K. (2011). O que é um ensaio-teórico? Revista de Administração Contemporânea, 15(2), 320-332. https://doi.org/10.1590/S1415-65552011000200010

Mirvis, P. H., \& Marks, M. L. (1992). The Human Side of Merger Planning: Assessing and Analyzing "Fit". Human Resource Planning, 15(3), 69-92.

Myers, S. C. (1977). Determinants of Corporate Borrowing. Journal of Financial Economics, 5(2), 147-175. https://doi.org/10.1016/0304-405X(77)90015-0

Morgan, G. (2000). Imagens da Organização. Edição Executiva. São Paulo: Atlas.

Nonaka, I., \& Takeuchi, H. (1997). Criação do Conhecimento na Empresa: como as empresas geram a dinâmica da inovação. Rio de Janeiro: Campus.

Peteraf, M. A. (1993). The cornerstones of competitive advantage: a resource-based view. Strategic Management Journal, 14(3), 179-191. https://doi.org/10.1002/smj.4250140303

Powell, S. (2003). Accounting for intangible assets: current requirements, key players and future directions. European Accounting Review, 12(4), 797-811. https://doi.org/10.1080/09638180310001628473

Ramanna, K., \& Watts, R. L. (2012). Evidence on the use of unverifiable estimates in required goodwill impairment. Review of Accounting Studies, 17, 749-780. https://doi.org/10.1007/s11142-012-9188-5

Reed, K. K., Lubatkin, M., \& Srinivasan, N. (2006). Proposing and testing an intellectual capital-based view of the firm. Journal of Management Studies, 43(4), 867-893. https://doi.org/10.1111/i.1467-

$\underline{6486.2006 .00614 . x}$

Rego, A., Souto, S., \& Cunha, M. P. (2007). Espiritualidade nas organizações, positividade e desempenho. Comportamento Organizacional e Gestão, 13(1), 7-36.

Rocha Loures, R. C. (2008). Educar e Inovar na Sustentabilidade. Curitiba: Unindus.

Sarasvathy, S. D. (1998). How do firms come to be? Towards a theory of the prefirm. Doctoral dissertation. Graduate School of Industrial Administration, Carnegie Mellon University, Pittsburgh, $118 \mathrm{f}$.

Seetharaman, A., Sreenivasan, J., Sudha, R., \& Yee, T. Y. (2006). Managing Impairment of Goodwill. Journal of Intellectual Capital, 7(3), 338-353. https://doi.org/10.1108/14691930610681447

Shah, H. A., Yasir, M., \& Miller, M. G. (2020). Analyzing Appreciative Inquiry as a Model of Change to build Relational Capital. Business \& Economic Review, 12(1), 1-24. http://dx.doi.org/10.22547/BER/12.1.1

Sveiby, K. E. (1998). A Nova Riqueza das Organizações - gerando e avaliando patrimônios de conhecimento. Rio de Janeiro: Campus.

Tittle, M. E. (2018). Using Appreciative Inquiry to Discover School Administrators' Learning Management Best Practices Development. Dissertation (Doctor of Philosophy). College of Management and Technology, Walden University, Minneapolis, $227 \mathrm{f}$.

Troxel, J. P. (2002). Appreciative Inquiry: an action research method for organizational transformation and its implication to the practice of group process facilitation. Millennia Consulting. Working Paper. Disponível em: http://facultylibrary.dmcodyssey.org/wpcontent/uploads/2016/04/Troxel-Appreciative-Inquiry8-02.pdf

Van der Haar, D., \& Hosking, D. M. (2004). Evaluating Appreciative Inquiry: A Relational Constructionist Perspective. Human Relations, 57(8), 1017-1036. https://doi.org/10.1177/0018726704045839

Varona, F. (2004). Todavía es posible soñar: Teoría apreciativa y Comunicación Organizacional. Organicom, 1(1), 14-33. https://doi.org/10.11606/issn.2238-2593.organicom.2004.138867

Wen, H., \& Moehrle, S. R. (2016). Accounting for goodwill: An academic literature review and analysis to inform the debate. Research in Accounting Regulation, 28(1), 11-21.

https://doi.org/10.1016/i.racreg.2016.03.002 
Whitney, D., \& Trosten-Bloom, A. (2001). The liberation of power: exploring how appreciative inquiry 'powers up the people'. In Appreciative inquiry: An emerging direction for organization development, 227-251.

Disponível em http://thinkingcircle.de/lit/appinq/appinq06.htm

\section{NOTAS}

\section{AGRADECIMENTOS}

Agradecemos os valiosos comentários e sugestões dos revisores anônimos da RCC.

\section{CONTRIBUIÇÃO DE AUTORIA}

Concepção e elaboração do manuscrito: K. V. Oliveira; P. R. B. Lustosa; A. O. Gonçalves.

Preparação e redação do rascunho inicial: K. V. Oliveira.

Desenvolvimento ou desenho de metodologia: A. O. Gonçalves.

Coleta de dados: P. R. B. Lustosa.

Análise de dados: K. V. Oliveira.

Revisão e aprovação: P. R. B. Lustosa; A. O. Gonçalves.

\section{CONJUNTO DE DADOS DE PESQUISA}

O conjunto de dados que dá suporte aos resultados deste estudo não está disponível publicamente.

\section{FINANCIAMENTO}

Não se aplica.

\section{CONSENTIMENTO DE USO DE IMAGEM}

Não se aplica.

\section{APROVAÇÃO DE COMITÊ DE ÉTICA EM PESQUISA}

Não se aplica.

\section{CONFLITO DE INTERESSES}

Não se aplica.

\section{LICENÇA DE USO}

Os Direitos Autorais para artigos publicados neste periódico são do autor, com direitos de primeira publicação para a Revista. Em virtude de aparecerem nesta Revista de acesso público, os artigos são de uso gratuito, com atribuições próprias, em aplicações educacionais, de exercício profissional e para gestão pública. A Revista adotou a licença Creative Commons Atribuição 4.0 Internacional - CC BY NC ND. Esta licença permite acessar, baixar (download), copiar, imprimir, compartilhar, reutilizar e distribuir os artigos desde que com a citação da fonte, atribuindo os devidos créditos de autoria. Nesses casos, nenhuma permissão é necessária por parte dos autores ou dos editores. Autores têm autorização para assumir contratos adicionais separadamente, para distribuição não-exclusiva da versão do trabalho publicada nesta revista (ex.: publicar em repositório institucional ou um capítulo de livro).

\section{PUBLISHER}

Universidade Federal de Santa Catarina. Curso de Ciências Contábeis e Programa de Pós-graduação em Contabilidade. Publicação no Portal de Periódicos UFSC. As ideias expressadas neste artigo são de responsabilidade de seus autores, não representando, necessariamente, a opinião dos editores ou da universidade.

\section{EDITORES}

Carlos Eduardo Facin Lavarda e Suliani Rover

\section{HISTÓRICO}

Recebido em: 09/07/2020 - Revisado por pares em: 06/08/2020 - Reformulado em: 09/10/2020 Recomendado para publicação em: 21/01/2021 - Publicado em: 22/03/2021

' O Gecon é um modelo teórico sobre a natureza das organizações que foi desenvolvido na Universidade de São Paulo USP pelo professor Armando Catelli, a partir do final da década de 1970 até o início dos anos 2000. Reúne de forma sistematizada conhecimentos de vários campos do conhecimento, principalmente de Teoria dos Sistemas, Administração, Economia e Contabilidade (Lustosa, 2017, p. 12-13).

ii Para informações adicionais sobre os projetos em andamento, ver os links: https://www.fasb.org/jsp/FASB/FASBContent_C/ProjectUpdateExpandPage\&cid=1176171566054\&pf=true https://www.ifrs.org/news-and-events/updates/iasb-updates/july-2019/

iii Samba Enredo de 1985 - G.R.E.S. Mocidade Independente de Padre Miguel: Ziriguidum 2001, Carnaval Nas Estrelas.

iv Em 2014 a ASTD mudou seu nome para ATD (Association for Talent Development). 